\title{
Synthesis and Characterization of Nanocrystalline Nickel - Cobalt Ferrites by Co-precipitation Method
}

\author{
Ali A. Ati, Zulkafli Othaman*, Shadab Dabagh, R. M. Rosnan, Samad Zare \\ Ibnu Sina Institute for Fundamental Science Studies, Universiti Teknologi Malaysia, 81310 Skudai Johor Baharu, Malaysia \\ *Corresponding Author: zulothaman@gmail.com
}

Article history:

Received 2 September 2014

Accepted 25 February 2015

\section{GRAPHICAL ABSTRACT}

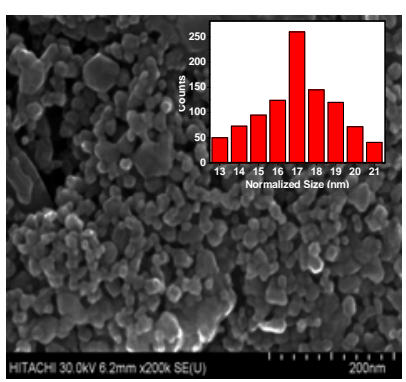

\begin{abstract}
Nano crystalline powders of Co-Ni ferrite compounds having the chemical formula $\mathrm{Co}_{(\mathrm{x})} \mathrm{Ni}_{(1-\mathrm{x})} \mathrm{Fe}_{2} \mathrm{O}_{4}(x$ $=0.0,0.2$ and 1.0) have been successfully synthesized by co-precipitation technique. These synthesized compounds are characterized by X-ray diffraction (XRD), field emission scan electron microscopy (FESEM), fourier transformed infrared (FTIR) spectrum, energy dispersive X-ray diffraction (EDX) and TGA-DTA. The XRD analyses of the samples sintered at $600{ }^{\circ} \mathrm{C}$ clearly show the formation of single cubic spinel structure. XRD patterns are further analyzed to calculate the lattice constant and jump length of charge carriers. Average crystalline sizes for ferrite powders are determined from XRD line using Debye-Scherrer's formula is found to be in the range of 16 to $19 \mathrm{~nm}$ with narrow size distribution. The Fourier transformed infrared (FTIR) spectrum characterization of the spinel ferrite structure sintered at $600{ }^{\circ} \mathrm{C}$ shows two fundamental strong band in the range $385-600 \mathrm{~cm}^{-1}$, which is attributed to different main metal-oxygen bands.
\end{abstract}

Keywords: Co-precipitation method, Nanoparticles, Co-Ni spinel ferrites, XRD, FT-IT

(C) 2015 Penerbit UTM Press. All rights reserved http://dx.doi.org/Xx.xxx/xxx.Xxx.xxx |

\section{INTRODUCTION}

In recent years, nanomaterials fabrication and their uses are emerging as a critical technology having applications in many industrial sectors [1, 2]. Among these materials, spinel ferrite structure of $\mathrm{MFe}_{2} \mathrm{O}_{4}$, where $\mathrm{M}$ represents the $\mathrm{Ni}, \mathrm{Mn}$ and $\mathrm{Zn}$ has been extensively studied due to electric, magnetic, chemical and mechanical properties. They currently used in wide application areas, such as microwave devices, memory cores, low energy inductors, transformer cores, deflection-yokes, loading coils, choke coils, electromagnetic interference (EMI), high-density magnetic recording and many other applications $[3,4]$. Nano-scale ferrites have led to production of modern magnetic materials because of their extraordinary magnetic property mainly in the radio frequency region. Many novel methods are used to synthesize ferrite nanoparticles, such as microwave-assisted flash combustion technique [5], solid state method [6, 7], solgel method [8], ball milling process [9], spray pyrolysis [10] and citrate method [11]. The solid state ceramic method for the preparation of ferrites has certain limitations such as long heating time and high temperature. This method also suffers from other disadvantages like chemical inhomogeneity, coarser particle size of the resulting material, impurity insertion during processing and losing of certain elements that leading to the formation of chemically inhomogeneous materials. The co-precipitation method has received considerable interest because it can offer simplicity, it is economic, and it is suitable for large-scale production with the good control of size and homogeneity [12]. In this paper, ferrite materials have been successfully synthesized by co-precipitation method. These ferrite materials are characterized using X-ray diffraction (XRD), Fourier transform spectrometer (FT-IR), field emission scanning electron microscope (FESEM), energy dispersive X-ray diffraction (EDX) and TGADTA techniques.

\section{EXPERIMENTS}

Ferrites nanomaterials with composition $\mathrm{Co}_{(\mathrm{x})} \mathrm{Ni}_{(1-\mathrm{x})} \mathrm{Fe}_{2} \mathrm{O}_{4}(x=0.0,0.2$ and 1.0$)$ are synthesized by chemical co-precipitation method. The chemicals used for synthesis ferrite samples are stoichiometric molar amounts of nickel(II) nitrate $\left.\left[\mathrm{Ni}\left(\mathrm{NO}_{3}\right)_{2} .6 \mathrm{H}_{2} \mathrm{O}\right)\right](98 \%$, Aldrich), cobalt(II) acetate $\left(\left[\mathrm{Co}\left(\mathrm{CH}_{3} \mathrm{COO}\right)_{2} .4 \mathrm{H}_{2} \mathrm{O}\right]\right.$ ( $98 \%$ Merck) and ferric nitrate $\left.\left[\mathrm{Fe}\left(\mathrm{NO}_{3}\right)_{3} .9 \mathrm{H}_{2} \mathrm{O}\right)\right](98.5 \%$ Merck). Ferric nitrate, nickel nitrate and cobalt acetates are dissolving in de-ionized water with constant magnetic stirring. The $(2.0 \mathrm{M})$ of $\mathrm{NaOH}$ solution is used as a precipitation agent. When the solution temperature reached $80{ }^{\circ} \mathrm{C}, \mathrm{NaOH}$ solution is added wisely drop by drop of the complex solution to kept the $\mathrm{pH}$ of the solution between 12.5 and 13. Then the precipitates are washed several times with de-ionized water until the $\mathrm{pH}$ solution become natural $(\mathrm{pH}=7)$. The precipitates of product are dried at $200{ }^{\circ} \mathrm{C}$ in oven overnight in order to remove the water contents than grinded to find powder and calcined at $600{ }^{\circ} \mathrm{C}$ temperature in electric furnace for $8 \mathrm{~h}$ with heating rate of $5{ }^{\circ} \mathrm{C}$ per/min to obtain the spinel ferrite phase. 


\section{RESULTS AND DISCUSSION}

Figure 1 shows the energy dispersive X-ray (EDX) spectra of the $\mathrm{Co}_{0.2} \mathrm{Ni}_{0.8} \quad \mathrm{Fe}_{2} \mathrm{O}_{4}$ sample confirm the presence of iron in addition to the cobalt, the nickel, carbon and the oxygen. The occurrences of peaks confirm the existence of nanoparticles composed purely of ferrite samples as observed in the FESEM images (Figure 2).

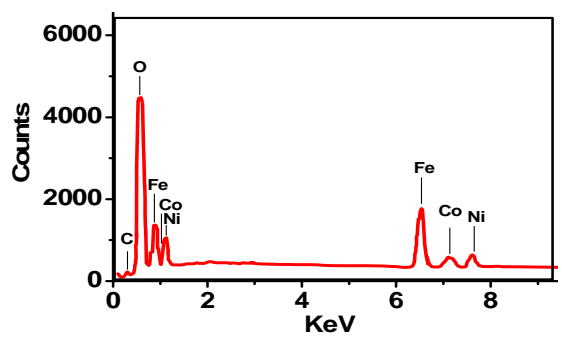

Figure 1. EDX spectra of $\mathrm{Co}(\mathrm{x}) \mathrm{Ni}_{(1-\mathrm{x})} \mathrm{Fe}_{2} \mathrm{O}_{4}$ nanoparticles after calcination at $600^{\circ} \mathrm{C}$.

The field emission scanning electron micrographs (FESEM) of $\mathrm{Co}_{(\mathrm{x})} \mathrm{Ni}_{(1-\mathrm{x})} \mathrm{Fe}_{2} \mathrm{O}_{4}$ samples sintered at 600 ${ }^{\circ} \mathrm{C}$ is illustrated in Figure 2. The micrographs demonstrates that the grains are well compacted with narrow size distribution (inset figure $2 \mathrm{a}$ ) and some of the particles are agglomerated. Nano scale of ferrite powders are obtained through co-precipitation method and the average crystalline size for all samples is given in table (1). The ferrite samples nanocrystalline consists of almost uniform particles size and reveals that the particles are more or less spherical in shape. The particles size is in a good agreement with the results obtained from X-ray analysis. The particles size is in a good agreement with the results obtained from X-ray analysis.
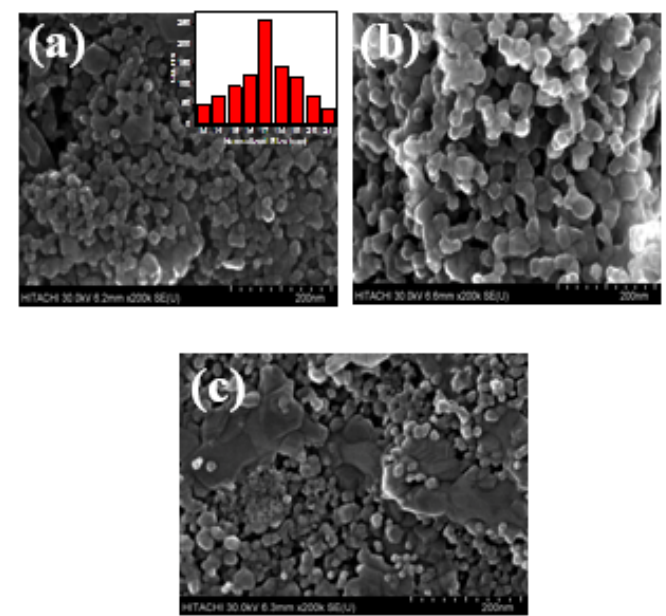

Figure. 2 FESEM micrograph of $\mathrm{Co}_{(\mathrm{x})} \mathrm{Ni}_{(1-\mathrm{x})} \mathrm{Fe}_{2} \mathrm{O}_{4}$ with $\mathrm{x}=0.0$ (a), $\mathrm{x}=0.2$ (b) and $\mathrm{x}=1.0$ (c) nanoparticles after calcination at $600{ }^{\circ} \mathrm{C}$.

The crystal structure and phase purity of the samples are characterized by XRD. The XRD spectra for the samples are shown in Figure 3. The X-ray diffraction patterns of the different chemical compositions $\mathrm{Co}_{(\mathrm{x})} \mathrm{Ni}_{(1-\mathrm{x})} \mathrm{Fe}_{2} \mathrm{O}_{4}(x=0.0,0.2$ and 1.0$)$ product at 600
${ }^{\circ} \mathrm{C}$ for $8 \mathrm{~h}$ show a pure-phase with a cubic spinel structure $\mathrm{NiFe}_{2} \mathrm{O}_{4}$ (JCPDS card no 10-0325), $\mathrm{CoFe}_{2} \mathrm{O}_{4}$ (JCPDS card no 22-1080) and Co doped nickel ferrite (JCPDS card no 40-1191). All the samples exhibit a poly-oriented structure with several peaks characteristic of other crystalline planes $(220,311,222$, $400,422,511$, and 440), which explain the single phase cubic spinel structure of $\mathrm{Co}_{(\mathrm{x})} \mathrm{Ni}_{(1-\mathrm{x})} \quad \mathrm{Fe}_{2} \mathrm{O}_{4}$. The crystalline size for each sample, calculated from full width at half maximum of the strongest XRD peak using the Debye-Scherrer's formula is found to be between 16 to $\sim 19 \mathrm{~nm}$.

The lattice parameters have been computed using the d-spacing values and respective ( $h k l$ ) parameters from the classical formula given in equation (1), which is illustrated in table 1

$a=\frac{\lambda}{2} \frac{\left[h^{2}+k^{2}+l^{2}\right]^{1 / 2}}{\sin \theta}$

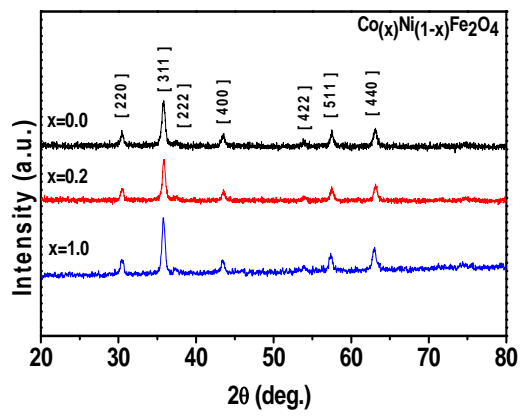

Figure. 3 XRD pattern of $\mathrm{Co}_{(\mathrm{x})} \mathrm{Ni}_{(1-\mathrm{x})} \mathrm{Fe}_{2} \mathrm{O}_{4}$ nanoparticles after calcination at $600{ }^{\circ} \mathrm{C}$.

The lattice constant has been affected by the cationic stoichiometry. The lattice parameters are found to increase almost linear by increase of Co content. The slow linear increase in lattice constant can be explained by the basic of the ionic radii. The ionic radius of $\mathrm{Ni}^{2+}$ $(0.69 \AA)$ replacement by slight larger $\mathrm{Co}^{2+}$ ions with an ionic radius of $(0.74 \AA)$ in the system $\mathrm{Co}_{(\mathrm{x})} \mathrm{Ni}_{(1-\mathrm{x})} \mathrm{Fe}_{2} \mathrm{O}_{4}$. The values of lattice parameter exhibit an almost linear dependence, thus obeying Vegard's law [13]. Lattice constant and crystalline size of these nanoparticles are summarized in Table 1.

Figure. 4 shows TGA-DTA curves of the powder precursor recorded under $\mathrm{N}_{2}$ atmosphere with a heating rate $10{ }^{\circ} \mathrm{C} \mathrm{min}-1$. The curve shows that the multistep continuous weight loss occurs from room temperature to $400{ }^{\circ} \mathrm{C}$.

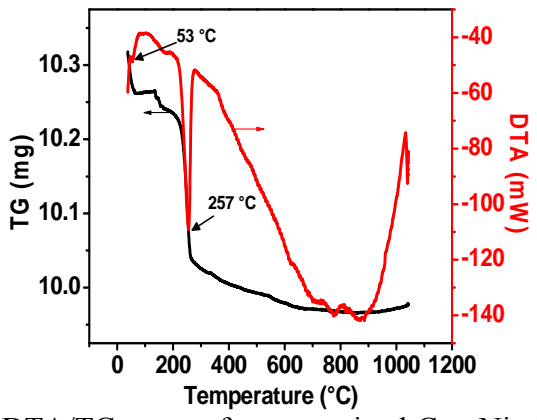

Figure. 4 DTA/TG curves for as-received $\mathrm{Co} 0.2 \mathrm{Ni}_{0} \mathrm{Fe}_{2} \mathrm{O}_{4}$ powder. 
Table 1. The high frequency wave, average particle size, calculated particle size by XRD, lattice constant and length jump of the samples.

\begin{tabular}{lcccr}
\hline Composition & $v_{1}\left(\mathrm{~cm}^{-1}\right)$ & $\begin{array}{c}\text { Average Particle size } \\
\text { Measured by FESEM } \\
(\mathrm{nm})\end{array}$ & $\begin{array}{c}\text { article size, calculated } \\
\text { by XRD }(\mathrm{nm})\end{array}$ & $\begin{array}{c}\text { Lattice const. } \\
\text { 'a' }(\AA)\end{array}$ \\
\hline $\mathrm{NiFe}_{2} \mathrm{O}_{4}$ & 595 & 17 & 16 & 8.330 \\
$\mathrm{Co}_{0.2} \mathrm{Ni}_{0.8} \mathrm{Fe}_{2} \mathrm{O}_{4}$ & 599 & 22 & 19 & 8.335 \\
$\mathrm{CoFe}_{2} \mathrm{O}_{4}$ & 592 & 20 & 17 & 8.361 \\
\hline
\end{tabular}

These weight loss appeared as exothermic peaks at $53^{\circ} \mathrm{C}$ and $257^{\circ} \mathrm{C}$, the exothermic peak at $53^{\circ} \mathrm{C}$ is attributed to the desorption of water physically absorbed on the surface of the powder and another exothermic peak is due to thermal decomposition of precursor. The endothermic process happens nearly 400 ${ }^{\circ} \mathrm{C}$, which corresponds to the formation and transition of crystalline spinel phase. The exothermic and endothermic regions in the DTA pattern are consistent with the change regions in the TG pattern. The TG curve shows no further weight loss above $600{ }^{\circ} \mathrm{C}$, confirming the formation of the stable cobalt-nickel ferrite.

FT-IR spectra vibration corresponds to metaloxygen bonds in the range $300-4000 \mathrm{~cm}^{-1}$ ferrite powders are shown in figure 5. The spectrum of $\mathrm{Co}_{(\mathrm{x})} \mathrm{Ni}_{(1-\mathrm{x})} \mathrm{Fe}_{2} \mathrm{O}_{4}$ cubic spinel structure exhibits two main metal-oxygen bands. The one with the high frequency wave $v_{1}$ is observed in the range $500-600 \mathrm{~cm}^{-1}$ is assigned to tetrahedral-metal stretching vibrations of $\left(\mathrm{M}_{\text {tetra }} \leftrightarrow O\right)$, whereas the lower frequency $v_{2}$ is usually observed in the range $385-450 \mathrm{~cm}^{-1}$ is attributed to the octahedral-metal stretching vibrations $\left(\mathrm{M}_{\text {oct }} \leftrightarrow \mathrm{O}\right)$ [14]. The stretching mode of the hydroxyl groups can be seen at $3419 \mathrm{~cm}^{-1}$ [15]. The peaks at $2922 \mathrm{~cm}^{-1}$ and $2825 \mathrm{~cm}^{-1}$ related to the stretching of $\mathrm{C}-\mathrm{H}$ band for $\left(\mathrm{CH}_{3}\right)$, and the bending of $-\mathrm{C}-\mathrm{H}$ can be seen at $1404 \mathrm{~cm}^{-1}$. In addition, there is a weak peak at $1627 \mathrm{~cm}^{-1}$ after the calcination, which is attributed to the $\mathrm{O}-\mathrm{H}$ band [16]. The difference in the $\mathrm{Fe}^{+3}-\mathrm{O}^{-2}$ distance for the octahedral and tetrahedral complexes results in the variation in band position.

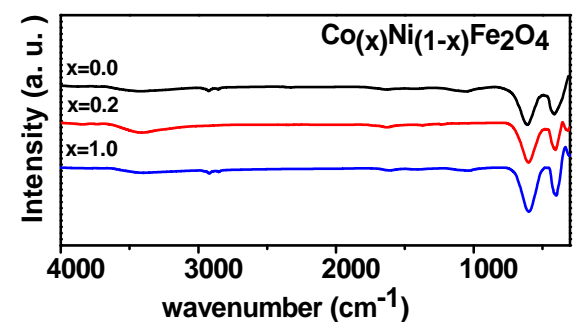

Figure.5 FT-IR spectra of $\mathrm{Co}_{(\mathrm{x})} \mathrm{Ni}_{(1-\mathrm{x})} \mathrm{Fe}_{2} \mathrm{O}_{4}$ Nanoparticles after calcination at $600^{\circ} \mathrm{C}$.

\section{Conclusion}

The chemical co-precipitation method have been employed to fabricate the cobalt substituted nickel spinel ferrite nanoparticles at $600{ }^{\circ} \mathrm{C}$ for $8 \mathrm{~h}$. XRD pattern of the ferrite samples reveal the formation of the cubic spinel phase. The average crystalline size for ferrite nanoparticles material has single cubic spinel structure with the range between 16 and $19 \mathrm{~nm}$ as determined by the X-ray diffraction. FESEM images confirm the nanocrystalline nature of the synthesized products. FTIR measurement for the ferrite powders shows two characteristic bands in the range $500-600 \mathrm{~cm}^{-1}$ and $385-$ $450 \mathrm{~cm}^{-1}$, which could be attributed to the tetrahedral and octahedral complexes respectively. The coprecipitation is found to be simple and economic method to produce high-quality ferrite nanosized powder with narrow size distribution.

\section{ACKNOWLEDGEMENTS}

The authors are thankful to Dr. Zulkafli for many valuable suggestions and critical reading of the manuscript. We are also grateful to Ibnu Sina Institute for Fundamental Science Studies and Physics Department of Universiti Teknologi Malaysia for technical supports and Ministry of Education for providing financial support for this project.

\section{REFERENCES}

[1] P. P. Hankare, P. D. Kamble, M. R. Kadam, K. S. Rane, P. N. Vasambekar, Materials Letters 61 (2007) 2769

[2] C. Fu, M. Syue, F. Wei, C. Cheng, C. Chou, J. Applied Physics 107 (2010) 09A519

[3] E. V. Gopalan, K. A. Malini, D. S. Kumar, Y. Yoshida, I. A. Al-Omari, S. Saravanan, M. R. Anantharaman, J. Physics Condensed Matter 21 (2009) 1

[4] J. Huo, M. Wei, Materials Letters 63 (2009) 1183

[5] K. Krieble, T. Schaeffer, J. Applied Physics 97 (2005) 10F101

[6] L. Zhao, Y. Cui, H. Yang, L. Yu, W. Jin, S. Feng, Materials Letters 60 (2006) 104

[7] A. Thakur, P. Mathur, M. Singh, J. Physics and Chemistry of Solids 68 (2007) 378

[8] G. Kumar, J. Chand, S. Verma, M. Singh, J. Physics D: Applied Physics 42 (2009) 155001

[9] M. C. Dimri, A. Verma, S. C. Kashyap, D.C. Dube,O.P. Thakur, C. Prakash, Materials Science and Engineering B 133 (2006) 42

[10] D.S. Jung, Y.C. Kang, j.MAgNETiSM AND MAGNETIC MATERIALS 321 (2009) 619

[11] K. Gagan, C Jagdish, V. Satish, M. Singh, J. Physics D: Applied Physics 40 (2009) 155001

[12] X. Guoxi, L. Yunqing, L. Yu Min, Materials Letters 58 (2004) 1146

[13] M.A. Gabal, S.S. Ata-Allah, Materials Chemistry and Physics 85 (2004) 104

[14] C.S. Zhang a, L.Yang, J. Magnetism and Magnetic Materials 324 (2012) 1469

[15] M. Aziz, S. S. Abbas, W. R.W. Baharom, W. Z. W. Mahmud, Materials Letters 74 (2012) 62

[16] A. K. Ghatage, S. C. Choudhari, S. A. Patil, J. Materials Science Letters 15 (1996) 1548 